In Crescendo. Institucional. 2016; 7(1): 114-132

Fecha de recepción: 6 de mayo de 2016

Fecha de aceptación: 17 de mayo de 2016

\title{
El Plan de Desarrollo Regional y su contribución ECONÓMICA A LA REGIÓN LA LIBERTAD
}

\section{Regional Development Plan and its Economic CONTRibution to La Libertad REGion}

\author{
Víctor Alejandro Síchez Muñoz* \\ Antonio Cholán Calderón**
}

\begin{abstract}
RESUMEN
T a presente investigación tuvo como propósito determinar el Plan de Desarrollo Regional Len la región La Libertad, así como elaborar una propuesta de plan de desarrollo regional. Se realizó una investigación en la que se determinaron las prioridades de las provincias de La Libertad en materia económica. La muestra estuvo conformada por las 12 provincias que representan los sectores económicos de La Libertad. Los aspectos que guiaron la propuesta fueron los fundamentos teóricos de la economía de desarrollo y la producción del país y con base a los resultados obtenidos se encontró que se prioriza la tecnificación de riego debido a que apenas un $25 \%$ de tierras tiene acceso al agua, el resto está en secano. Se concluye que las provincias de mayor producción y desarrollo son Bolívar, Pacasmayo, Virú y otros.
\end{abstract}

Palabras claves: Plan de Desarrollo, desarrollo económico, región, sector económico, potencial turístico, potencial económico.

\begin{abstract}
This research aims to determine the regional development plan in the region Freedom and develop a proposal for the regional development plan that will allow the region to develop economically. An investigation where the priorities of the provinces of La Libertad in economic determined was performed. The sample consisted of twelve provinces representing economic sectors of La Libertad. The aspects that guided the proposal were the theoretical foundations of the economy development and production of the country
\end{abstract}

\footnotetext{
* Correo electrónico: vsichez68@hotmail.com

** Correo electrónico: a_cholan@hotmail.com
} 
and based on the results found that the modernization of irrigation is prioritized due to only $25 \%$ is irrigated, the rest is in rainfed, and concludes that the provinces with the highest production and development are Bolívar, Pacasmayo, Virú and others.

Keywords: Development Plan, economic development, region, economic sector, tourism potential, economic potential.

\section{INTRODUCCIÓN}

Los procesos de plan de desarrollo regional adquieren actualmente una significación estratégica en la gestión pública y los procesos de reforma del Estado. No solo por el contexto de transformaciones que la globalización ha generado en el ámbito internacional, sino porque existe actualmente cada vez más una necesidad de afirmación de las identidades regionales, los procesos de gestión económica territorial, las políticas de descentralización y democratización de la toma de decisiones públicas.

La región La Libertad afronta hoy una diversidad de retos y desafíos. Los procesos de desarrollo que actualmente experimenta, responden a los efectos que la globalización viene imponiendo a escala mundial; sin embargo, estos procesos tienen que ver también con dinámicas regionales y procesos localizados en lugares donde se establecen relaciones que responden a patrones de desarrollo que siguen los parámetros impuestos a escala global, pero que no en todos los casos terminan incorporados o se incorporan a estos, sino más bien son marginalizados y excluidos.

Las regiones y los países son articulados en función de los intereses de los mercados financieros, las operaciones de servicios bursátiles y las inversiones; pero al mismo tiempo son marginalizados y afectados por desigualdades crecientes en la concentración de recursos estratégicos y actividades entre regiones y países y al interior de estos. Los que absorben inversiones son dinamizados en actividades económicas especializadas que responden a los mercados globales; pero muchas veces sus poblaciones no necesariamente se benefician, sino que terminan afectadas por la agudización de la pobreza y la marginalización.

La interrogante a resolver es ¿cómo enfrentar los retos y desafíos que estos procesos generan en una región como La Libertad? Las respuestas surgen del proceso de actualización del Plan Regional de Desarrollo Concertado, que asume como uno de sus presupuestos centrales que es posible definir la orientación de futuro del desarrollo regional para los próximos años.

El proceso de actualización del Plan Regional de Desarrollo Concertado (PRDC) fue iniciado formalmente el 31 de octubre de 2008, con la firma de la Resolución Ejecutiva Regional N. ${ }^{3}$ 3114-2008-GR-LL/Pre., del Gobierno Regional La Libertad, que estableció el sistema de organización, las responsabilidades y las funciones que cumplirían los diversos actores involucrados en este proceso.

El PRDC ha sido formulado de manera descentralizada y participativa, habiendo convocado a los agentes del desarrollo a sesiones de trabajo en las 12 provincias de La Libertad. 
La experiencia del PRDC muestra que es necesario consolidar los esfuerzos que vienen desplegándose desde el Gobierno Regional La Libertad y desde organizaciones de la sociedad civil, como la Mesa de Concertación para la Lucha contra la Pobreza, para gestionar de manera planificada el desarrollo regional.

Es urgente fortalecer capacidades en el Gobierno Regional y la sociedad civil para consolidar la experiencia de actualización del PRDC. Mejorar competencias en cuadros técnicos, fortalecer liderazgos sociales y políticos, consolidar la institucionalidad democrática, potenciar el uso de sistemas de producción y gestión de información.

No es posible dejar de mencionar que el desarrollo es, fundamentalmente, un proceso de ampliación de oportunidades de la gente, lo cual se logra a través de la formación de capacidades. El desarrollo, por lo tanto, no se reduce al ingreso y los aspectos vinculados a la dimensión económica, o la construcción de vías y edificaciones. Las dimensiones del desarrollo incluyen lo social, lo cultural, lo ambiental, lo político-institucional, lo físico, lo económico. Por lo tanto, el desarrollo debe abarcar más que la expansión de la riqueza y los ingresos, más que el crecimiento y la construcción de infraestructura. Su objetivo central es el ser humano.

Por ello, el proceso desplegado supone retos para los actores y agentes involucrados en esta experiencia. Compromisos éticos tanto a nivel individual como colectivo, con su gente, su territorio, su pasado, presente y futuro.

La experiencia ha generado más que un documento o una herramienta de gestión, una oportunidad para que diversos actores sociales y agentes económicos, liderados por el Gobierno Regional, trabajen juntos de manera concertada y con una orientación común.

Evidentemente, este asunto supone y exige voluntad política para hacer que los acuerdos establecidos en el marco del proceso de planificación puedan ser llevados a la práctica y no terminen archivados en un anaquel de una oficina. Voluntad política no solo de las autoridades sino también de los representantes de la sociedad civil de La Libertad, para concertar esfuerzos, articular iniciativas, compartir perspectivas, manejar conflictos, negociar demandas, construir democracia participativa.

El PRDC es una invitación para afrontar conjuntamente, como sociedad regional, los retos y desafíos que La libertad tiene y tendrá que afrontar hoy y en los próximos años y que guiarán la articulación de las acciones del gobierno regional, para elevar las condiciones de bienestar de la ciudadanía y sentar las bases de un cambio de enfoque de la acción pública.

\section{Potencialidades regionales}

El territorio de La Libertad es privilegiado en cuanto a recursos naturales, en él encontramos casi todos los pisos altitudinales descritos por Javier Pulgar-Vidal (excepto selva baja), por lo tanto, posee ventajas comparativas para desarrollar distintos tipos de cultivos, diferentes variedades forestales; posee, además, diversidad de fuentes de agua (manantiales, lagunas, nacientes de ríos), reservas de oro y de carbón de piedra, asimismo, importantes recursos turísticos, arqueológicos, naturales, etc. 
La preocupación por identificar fuentes de agua y zonas con vocación forestal obedece, entre otras razones, a la necesidad de abordar el desafío del cambio climático del siglo XXI; como se sabe, el calentamiento global ya es un hecho y uno de los mecanismos por los cuales afecta el desarrollo humano es a través de lo que se denomina "el estrés por falta de agua e inseguridad de agua"; por ello, las estrategias de conservación de fuentes de agua y programas de forestación y reforestación resultan hoy muy relevantes. De igual modo, se identifican las principales cuenca hidrográficas, pues su manejo integral se constituye en un medio para garantizar desarrollo humano sustentable.

En la provincia de Gran Chimú son impostergables la forestación con plantaciones maderables y no maderables en los pisos ecológicos alto y medio y en los corredores económicos priorizados de la provincia. Esto se justifica porque este sector es uno de los más importantes motores de progreso y desarrollo de esta región. Así, el Plan de Desarrollo Regional Concertado de la Libertad (2003) expone el potencial forestal de esta provincia, ya que, cuenta con aproximadamente con 57000 has aptas para las plantaciones forestales, destacando el distrito de Cascas (zona de Chepate, Tillampá, Llapo-Samaná y el bosque natural de Cachil y Marmot (Compín) y la parte alta del distrito Chugui-Quilca. Es decir, con esta cantidad de hectáreas se puede impulsar notablemente el desarrollo de la región. Por su parte, en un nivel medio, se fomenta el desarrollo integral agrícola y pecuario en cultivos y crianzas priorizadas en la parte alta y media de la provincia. De allí que el plan estratégico de desarrollo integral y sustentable (2003) expone como potencial agrícola el clúster de la uva (1700 productores con cerca de 1000 has), destaca también el cultivo de arroz, maíz amarrillo duro, papa, camote y trigo. Posee 18833 has de área agrícola, de las cuales $25 \%$ están bajo riego y el $75 \%$ en secano.

En Otuzco se prioriza un programa de infraestructura de riego de la cuenca media del río Moche y el programa integral de fortalecimiento de clúster de productos agrícolas tradicionales y alternativos andinos, mientras que en un programa de generación de valor agregado en los productos metálicos. La prioridad para la infraestructura de riego y el fortalecimiento del clúster de productos agrícolas, son los pilares para el desarrollo de esta zona. Así, el Programa Regional de Competitividad (2006) expone un potencial agrícola en lo que se destacan cultivos alto andinos (papa, menestras, cereales, cebada, trigo, frutales, granadilla, palta, piña). Destacan en producción, los distritos de Otuzco, Salpo y Mache. El Plan de Desarrollo Regional (2003) menciona también zonas de minería informal ubicada en Pachín Alto y Pollo (Otuzco) y las minerías informales de Salpo, Chuquizongo y Usquil. Así, en el Plan de Competitividad de la Libertad (2006) se presentan las fuentes de agua como potenciales turísticas, ya que cuenta con 6 lagunas entre las que destacan las lagunas de Usgón, Brava y Negra, ubicadas en las faldas del cerro Pelón Chico. Estas dan nacimiento al río Huacapongo, formador del Río Virú. Para el plan estratégico nacional de turismo (2008), existen zonas en esta región con grandes potenciales turísticos que se van descubriendo para el mejoramiento del sector. El plan de competitividad (2016) nos presenta potenciales forestales y agrícolas, demostrados en su potencial agrícola, ya que cuenta con 42289 has de áreas agrícolas, de las cuales el 16\% están bajo riego y el 89\% en secano. 
En el aspecto económico, el Plan de Desarrollo Integral de la región La Libertad (2003), en la provincia se destaca el potencial agrícola y el potencial forestal; se dispone de 265896 has, el 15.58\% de áreas agrícolas disponiendo de riego solo el 4,31\% de esta superficie, lo cual limita fuertemente la actividad agropecuaria. Informaciones de la Municipalidad de Santiago de Chuco (2006) señalan que los productos más cultivados son: cereales: trigo, cebada, maíz; tubérculos: papa, oca, olluco; hortalizas y árboles frutales.

Se muestra un plan de desarrollo regional en donde se prioriza en un nivel alto las instalaciones del cultivo de palto, la implementación de obras mecánico-estructurales de la conservación de suelos, los pastos naturales. De allí que para el plan de competitividad de la provincia de Sánchez Carrión (2006), se destacan los potenciales agrícola forestal, en donde se cuenta con 60615 has de esta área agrícola y aproximadamente 72672 has aptas para plantaciones forestales. Así mismo el plan estratégico de desarrollo Huamachuco (2001) señala que existen zonas de pasturas, fuentes de agua y zonas minerales.

Se evidencia un plan de desarrollo regional donde se priorizan el programa de mejoramiento y construcción de infraestrutura y tecnificación de riego. Así, el plan de desarrollo regional concertado (2003) señala como potenciales el agrícola y el forestal, desarrollar las zonas mineras y pasturales, así como sus fuentes de agua. Por su parte, el plan estratégico nacional (2008), mientras que el Cerplan (2009), sostiene que existen grandes yacimientos de minerales.

El plan de desarrollo regional prioriza el programa de fortalecimiento de las capacidades competitivas de los productores agropecuarios, es decir, para contribuir con el desarrollo económico de esta provincia se tiene que impulsar este plan de desarrollo como potencial macroestructural. El plan de desarrollo regional (2010), explica que parte de la población se dedica a la extracción de oro.

El plan de desarrollo regional prioriza el programa de optimización de riego, su generación de empleo alto. De esta manera el programa regional de competitividad (2006) explica: "Ascope es un pueblo que por ser capital de Provincia genera desplazamientos todos los días pero que lamentablemente son motivados por trámites documentarios que se realizan, posee las cualidades perfectas para desarrollar diferentes tipos de turismo y de los que sobre la base de sus productos turísticos puede mejorar su actividad económica".

El plan estratégico de desarrollo integral (2003) señala los recursos productivos, agrícola y turísticos, los cuales constituyen la base de nuestra grandeza.

En el plan de desarrollo regional se prioriza todos los programas de reconversión agraria, mejoramiento de la productividad, desarrollo pecuario, el turismo. Así, el programa regional de competitividad (2006) señala que Chepén tiene su base económica en la agricultura, que ocupa el 43,1\% de la PEA provincial, cultivando arroz, el maíz y la caña de azúcar que representa el 94\% de la superficie cosechada. También el plan de desarrollo regional (2010) señala que la industria en proceso de desarrollo, predominando 
la agroindustria, el turismo se presenta como alternativa para dinamizar la economía de Provincial.

En el plan de desarrollo regional se priorizan todos los programas, como el mejoramiento de la infraestructura de riego, el impacto ambiental y la capacidad de realización con nuestros recursos; en consecuencia, para contribuir con el desarrollo económico de esta provincia se impulsa este plan de desarrollo económico como potencial macroestructural. Así, el programa de competitividad (2006) explica que en el estudio de impacto ambiental, es decir es necesario impulsar el desarrollo económico en forma organizada para levantar sus deficiencias con el nivel económico de la provincia de Pacasmayo.

El plan de desarrollo regional se prioriza el programa de desarrollo ganadero, el impacto ambiental, desarrollo del proyecto, innovación y mejora de la competitividad de la industria metal-mecánica y la búsqueda constante para reducir la pobreza. En este sentido CCL y WK, UPAO (2010) explica: "Trujillo concentra más del 6,8\% de agentes económicos de los registrados, destaca el sector financiero, minero, eléctrico, de agua, inmobiliario y empresarial".

Asimismo, el plan estratégico de desarrollo integral y sostenible de Trujillo (2003), señala que Trujillo es un centro agroindustrial; exporta espárragos gracias al impulso del proyecto Chavimochic; en calzado destacan grandes curtiembres. Para el plan estratégico regional exportador (2004) señala que tiene la particularidad de haber conformado un conglomerado (clúster) industrial con una dinámica de comercialización y producción propia, en metal mecánica está compuesto principalmente por pequeñas y medianas empresas, mantenimiento de piezas y carrocerías. Asimismo, el plan de desarrollo concertado de la Libertad (2003) expresa que el comercio es una de las actividades más desarrolladas en la ciudad en los rubros de productos agropecuarios, alimentos, bebidas y materiales de construcción, asimismo, se desarrolla el comercio exterior en gran medida.

En el plan de desarrollo regional se prioriza el programa de fortalecimiento de capacidades técnicas y organizacionales en pequeños productores agropecuarios, el impacto ambiental y el parque agroecológico y turístico de Guadalupito y Guañape. Así, el plan de desarrollo concertado de la provincia de Virú (2007), expresa que su agricultura es muy diversa, sembrándose alcachofa, pimiento piquillo, berenjena, espárrago verde y blanco. Presenta importantes atractivos turísticos que al ser explotados adecuadamente contribuirán a beneficiar el desarrollo socioeconómico de la zona. Asimismo, el plan estratégico regional (2009) destaca los complejos arqueológicos de Zaraque, perteneciente a la cultura Virú, el complejo arqueológico Keneto, los castillos de San Juan y Huancaco y numerosas Huacas.

\section{MATERIAL Y MÉTODOS}

\section{OBJETO DE ESTUDIO}

Como objeto de estudio abordado en la presente investigación consideramos a la población de la región La Libertad, con sus características económicas, sociales y culturales. Asimismo, las características de las redes viales existentes. 


\section{INSTRUMENTOS}

Se utilizaron los siguientes instrumentos:

- Bibliotecas de las provincias que representan los sectores económicos de la región La Libertad.

- Encuestas y entrevistas a funcionarios y empleados de la entidad que han intervenido en el presente estudio.

\section{MÉTODOS Y TÉCNICAS}

Método universal:

A) Método científico. Se empleó este método por ser el procedimiento que se aplica al ciclo de la investigación, en el marco de cada problema de conocimiento de los sectores de la región la Libertad, empezando por la realidad (hecho, suceso o fenómeno) económica de la región La Libertad.

B) Métodos generales

- Método inductivo-deductivo. Para lograr el análisis partiendo de casos concretos hacia la generalidad de la problemática del material de estudio.

- Método comparativo. Que nos ha permitido el estudio analítico y comparativo de las diversas interpretaciones de las leyes, en especial a lo concerniente a procesos de amparo, sobre declaratoria de inaplicabilidad de una norma.

Métodos especiales

- Método hermenéutico-jurídico. Que nos ha permitido la interpretación, tanto de las leyes de nuestra normativa nacional y de las diversas tendencias y criterios que se han producido.

Técnicas

A) Técnicas documentales:

- Recopilación documental. Mediante esta técnica se recolectó información de los diferentes libros, de autores nacionales y extranjeros, leyes y jurisprudencia del derecho nacional y comparado, en el análisis de las sentencias recaídas en procesos de amparo, desde la perspectiva de los efectos jurídicos de estas en la práctica. Asimismo, se analizarán diversas sentencias del Tribunal Constitucional, sobre el tema del amparo contra normas legales y del control difuso.

- Fichaje. Para registrar información bibliográfica de libros, ensayos y artículos publicados en diversas monografías y revistas especializadas. Entre ellas tenemos las siguientes fichas:

- Nemotécnicas

- De resumen 


\section{- De comentario}

B) Técnicas personales:

- Encuesta. Para la toma de información se realizó una encuesta a 30 trabajadores del Gobierno Regional de Trujillo.

- Observación. Directa e indirecta; esta técnica nos permitió tener acceso directo sobre los hechos que suceden en la realidad, en lo referente a nuestro tema de estudio.

\section{RESULTADO Y DISCUSIÓN}

Resultados de evaluación del sector económico de la región La Libertad.

Tabla 1. Sector económico de la provincia de Ascope

\begin{tabular}{|c|c|c|c|c|c|}
\hline $\begin{array}{l}\text { Criterios de } \\
\text { evaluación }\end{array}$ & $\begin{array}{l}\text { Programa de } \\
\text { desarrollo } \\
\text { integral } \\
\text { del sector } \\
\text { turismo }\end{array}$ & $\begin{array}{l}\text { Programa de } \\
\text { desarrollo de } \\
\text { la maricultura } \\
\text { en el distrito } \\
\text { de Rázuri }\end{array}$ & $\begin{array}{l}\text { Programa de } \\
\text { optimización } \\
\text { del riego en la } \\
\text { cuenca baja del } \\
\text { río Chicama }\end{array}$ & $\begin{array}{l}\text { Programa } \\
\text { integral de } \\
\text { desarrollo de } \\
\text { productos } \\
\text { agrícolas } \\
\text { exportables }\end{array}$ & $\begin{array}{l}\text { Programa integral } \\
\text { de mejoramiento de } \\
\text { la competitividad } \\
\text { del clúster pecuario } \\
\text { en la provincia de } \\
\text { Ascope }\end{array}$ \\
\hline $\begin{array}{l}\text { Generación } \\
\text { de empleo e } \\
\text { ingresos }\end{array}$ & 4 & 5 & 5 & 3 & 3 \\
\hline $\begin{array}{l}\text { Impacto } \\
\text { ambiental }\end{array}$ & 3 & 4 & 4 & 5 & 3 \\
\hline $\begin{array}{l}\text { Novedad del } \\
\text { proyecto }\end{array}$ & 3 & 5 & 5 & 4 & 4 \\
\hline $\begin{array}{l}\text { Capacidad de } \\
\text { realización } \\
\text { con nuestros } \\
\text { recursos }\end{array}$ & 2 & 2 & 4 & 5 & 3 \\
\hline $\begin{array}{l}\text { Impacto en la } \\
\text { reducción de la } \\
\text { pobreza. }\end{array}$ & 4 & 5 & 4 & 4 & 4 \\
\hline $\begin{array}{l}\text { Suma de } \\
\text { Puntajes }\end{array}$ & 16 & 21 & 22 & 21 & 17 \\
\hline Promedio & 3.2 & 4.2 & 4.4 & 4.2 & 3.4 \\
\hline Prioridad & 6 & 3 & 1 & 2 & 4 \\
\hline
\end{tabular}

Fuente: Evaluación de criterio priorizada de base de datos

Para Ascope en el aspecto económico se refleja una prioridad alta en el programa de optimización del riego en la cuenca baja del río Chicama, donde la generación de empleos e ingresos es alto, y la novedad del proyecto también; mientras que la menor prioridad la tiene el programa de desarrollo integral del sector turismo. Esto se debe a que en Ascope 
se tiene conciencia de que para desarrollar el sector turismo primero se debe priorizar la optimización del riego, ya que esto permitirá aflorar campos verdes y naturales para varios sectores.

Para la provincia de Bolívar se prioriza el programa de mejoramiento y construcción de infraestructura y tecnificación de riego, donde la generación de empleo e ingresos y el impacto ambiental es alto; mientras que la menor prioridad la tiene el programa de mejoramiento de servicios turísticos. Principalmente, en Bolívar se busca garantizar la infraestructura como elemento para el sector turístico (véase Tabla 2).

En Chepén se priorizan todos los programas desde el programa para la reconversión agraria y el mejoramiento de la productividad agroindustrial hasta el programa para el desarrollo pecuario en la provincia de Chepén, considerando el mejoramiento de la infraestructura y el programa de desarrollo integral del turismo (véase Tabla 3).

Tabla 2. Sector económico de la provincia de Bolívar.

\begin{tabular}{|c|c|c|c|c|c|}
\hline $\begin{array}{l}\text { Criterios de } \\
\text { evaluación }\end{array}$ & $\begin{array}{l}\text { Programa de } \\
\text { impulso al } \\
\text { desarrollo de } \\
\text { productos agrícolas } \\
\text { alternativos y } \\
\text { transformación } \\
\text { industrial de } \\
\text { derivados agrícolas }\end{array}$ & $\begin{array}{c}\text { Fortalecimiento } \\
\text { de capacidades } \\
\text { para la puesta } \\
\text { en valor y } \\
\text { mejoramiento } \\
\text { de la } \\
\text { producción de } \\
\text { la papa nativa }\end{array}$ & $\begin{array}{c}\text { Programa de } \\
\text { mejoramiento } \\
\text { de servicios } \\
\text { turísticos }\end{array}$ & $\begin{array}{l}\text { Programa de } \\
\text { mejoramiento y } \\
\text { construcción de } \\
\text { infraestructura y } \\
\text { tecnificación de } \\
\text { riego en Bolívar }\end{array}$ & $\begin{array}{c}\text { Programa integral de } \\
\text { desarrollo ganadero } \\
\text { en los distritos } \\
\text { de Uchucmarca: } \\
\text { Chivane, Quinuas, } \\
\text { Llamactambo, } \\
\text { Cascapuy, } \\
\text { Chilcahuayco, Andul, } \\
\text { Santa Luisa }\end{array}$ \\
\hline $\begin{array}{l}\text { Generación } \\
\text { de empleo e } \\
\text { ingresos }\end{array}$ & 5 & 5 & 3 & 5 & 4 \\
\hline $\begin{array}{l}\text { Impacto } \\
\text { ambiental }\end{array}$ & 4 & 4 & 5 & 5 & 5 \\
\hline $\begin{array}{l}\text { Novedad del } \\
\text { proyecto }\end{array}$ & 3 & 3 & 5 & 4 & 4 \\
\hline $\begin{array}{l}\text { Capacidad de } \\
\text { realización } \\
\text { con nuestros } \\
\text { recursos }\end{array}$ & 3 & 4 & 2 & 3 & 2 \\
\hline $\begin{array}{l}\text { Impacto en la } \\
\text { reducción de } \\
\text { la pobreza }\end{array}$ & 5 & 4 & 3 & 4 & 5 \\
\hline $\begin{array}{l}\text { Suma de } \\
\text { puntajes }\end{array}$ & 20 & 20 & 18 & 21 & 20 \\
\hline Promedio & 4.00 & 4.00 & 3.60 & 4.20 & 4.00 \\
\hline Prioridad & Alta & Alta & Alta & Alta & Alto \\
\hline
\end{tabular}

Fuente: Evaluación de criterio priorizada de base de datos 
Tabla 3. Sector económico de la provincia Chepén

\begin{tabular}{|c|c|c|c|c|}
\hline $\begin{array}{l}\text { Criterios de } \\
\text { evaluación }\end{array}$ & $\begin{array}{c}\text { Programa de } \\
\text { desarrollo integral } \\
\text { del turismo en } \\
\text { la provincia de } \\
\text { Chepén }\end{array}$ & $\begin{array}{c}\text { Programa para el } \\
\text { mejoramiento de } \\
\text { la infraestructura } \\
\text { de Riego en la } \\
\text { provincia de } \\
\text { Chepén }\end{array}$ & $\begin{array}{c}\text { Programa para el } \\
\text { desarrollo pecuario } \\
\text { en la provincia de } \\
\text { Chepén }\end{array}$ & $\begin{array}{l}\text { Programa para la } \\
\text { reconversión agraria } \\
\text { y mejoramiento de la } \\
\text { productividad de la } \\
\text { producción agroindustrial } \\
\text { en la provincia de Chepén }\end{array}$ \\
\hline $\begin{array}{l}\text { Generación de } \\
\text { empleo e ingresos }\end{array}$ & 5 & 5 & 5 & 5 \\
\hline Impacto ambiental & 3 & 4 & 2 & 3 \\
\hline $\begin{array}{l}\text { Novedad del } \\
\text { proyecto }\end{array}$ & 4 & 4 & 4 & 5 \\
\hline $\begin{array}{l}\text { Capacidad de } \\
\text { realización con } \\
\text { nuestros recursos }\end{array}$ & 3 & 3 & 2 & 2 \\
\hline $\begin{array}{l}\text { Impacto en la } \\
\text { reducción de la } \\
\text { pobreza }\end{array}$ & 4 & 5 & 5 & 5 \\
\hline $\begin{array}{l}\text { Suma de } \\
\text { Puntajes }\end{array}$ & 19 & 21 & 18 & 21 \\
\hline Promedio & 3.80 & 4.20 & 3.60 & 4.20 \\
\hline Prioridad & Alto & Alto & Alto & Alto \\
\hline
\end{tabular}

Fuente: Evaluación de criterio priorizada de base de datos

Tabla 4. Sector económico de la provincia Gran Chimú

\begin{tabular}{|c|c|c|c|c|c|}
\hline $\begin{array}{l}\text { Criterios de } \\
\text { evaluación }\end{array}$ & $\begin{array}{l}\text { Forestación con } \\
\text { plantaciones } \\
\text { maderables y } \\
\text { no maderables } \\
\text { en los pisos } \\
\text { ecológicos alto } \\
\text { y medio y en } \\
\text { los corredores } \\
\text { económicos } \\
\text { priorizados de } \\
\text { la provincia }\end{array}$ & $\begin{array}{l}\text { Fomento al desarrollo } \\
\text { integral agrícola y } \\
\text { pecuario en cultivos } \\
\text { y crianzas priorizadas } \\
\text { en la parte alta y } \\
\text { media de la provincia, } \\
\text { en armonía con la } \\
\text { actividad minera } \\
\text { y en ámbitos que } \\
\text { promuevan desarrollo } \\
\text { sostenible }\end{array}$ & $\begin{array}{l}\text { Puesta en valor } \\
\text { del corredor } \\
\text { turístico } \\
\text { Cascas, } \\
\text { Marmot y } \\
\text { Lucma (bosque } \\
\text { de Cachil, } \\
\text { Cristo de las } \\
\text { Rocas, Baños } \\
\text { Chimú) }\end{array}$ & $\begin{array}{l}\text { Fortalecimiento } \\
\text { de las cadenas } \\
\text { productivas de } \\
\text { frutales (lúcuma, } \\
\text { granadilla, palto, } \\
\text { chirimoya) en la } \\
\text { zona media y baja } \\
\text { de la provincia }\end{array}$ & $\begin{array}{l}\text { Crianza de } \\
\text { animales } \\
\text { menores cuy y } \\
\text { conejo y aves } \\
\text { de corral, en } \\
\text { los corredores } \\
\text { priorizados de } \\
\text { la provincia } \\
\text { Gran Chimú }\end{array}$ \\
\hline $\begin{array}{l}\text { Generación de } \\
\text { empleo e ingresos }\end{array}$ & 5 & 4 & 3 & 5 & 5 \\
\hline $\begin{array}{l}\text { Sostenibilidad } \\
\text { ambiental }\end{array}$ & 5 & 3 & 3 & 5 & 4 \\
\hline $\begin{array}{l}\text { Novedad del } \\
\text { proyecto }\end{array}$ & 5 & 4 & 4 & 5 & 5 \\
\hline $\begin{array}{l}\text { Capacidad de } \\
\text { realizar con } \\
\text { nuestros recursos }\end{array}$ & 3 & 2 & 4 & 2 & 2 \\
\hline $\begin{array}{l}\text { Posibilidad de } \\
\text { financiarlos }\end{array}$ & 5 & 3 & 4 & 5 & 5 \\
\hline Suma de puntajes & 23 & 16 & 18 & 22 & 21 \\
\hline Promedios & 4.6 & 3.2 & 3.6 & 4.5 & 4.2 \\
\hline Prioridad & 1. Alto & 5. Media & 4. Alto & 2. Alto & 3. Alto \\
\hline
\end{tabular}

Fuente: Evaluación de criterio priorizada de base de datos 
En la provincia de Gran Chimú se priorizan en un nivel alto la forestación con plantaciones moderables y no moderables en los pisos ecológicos alto y medio y en los corredores económicos priorizados en la provincia, mientras que en un nivel medio se fomenta el desarrollo integral agrícola y pecuario en cultivos y crianzas priorizadas en la parte alta y media de la provincia.

Tabla 5. Sector económico del provincia Julcán

\begin{tabular}{|c|c|c|c|c|}
\hline $\begin{array}{l}\text { Criterios de } \\
\text { Evaluación }\end{array}$ & $\begin{array}{c}\text { Mejoramiento y } \\
\text { construcción de } \\
\text { infraestructura y } \\
\text { tecnificación de riego en } \\
\text { Julcán }\end{array}$ & $\begin{array}{l}\text { Programa de } \\
\text { Desarrollo } \\
\text { Agrícola en la } \\
\text { Provincia de } \\
\text { Julcán }\end{array}$ & $\begin{array}{l}\text { Programa integral de } \\
\text { sensibilización y puesta } \\
\text { en valor de los recursos } \\
\text { turísticos. }\end{array}$ & $\begin{array}{c}\text { Programa de } \\
\text { mejoramiento del } \\
\text { subsector pecuario en la } \\
\text { provincia de Julcán }\end{array}$ \\
\hline $\begin{array}{l}\text { Generación } \\
\text { de empleo e } \\
\text { ingresos }\end{array}$ & 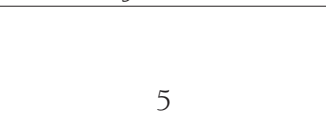 & 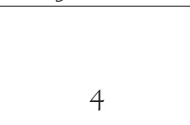 & 4 & 5 \\
\hline $\begin{array}{l}\text { Impacto } \\
\text { ambiental }\end{array}$ & 4 & 3 & 3 & 3 \\
\hline $\begin{array}{l}\text { Novedad del } \\
\text { proyecto } \\
\text { Capacidad de } \\
\text { realización } \\
\text { con nuestros } \\
\text { recursos }\end{array}$ & 3 & 3 & 5 & 3 \\
\hline $\begin{array}{l}\text { recursos } \\
\text { Impacto en la } \\
\text { reducción de la } \\
\text { pobreza. }\end{array}$ & 4 & 4 & 4 & 5 \\
\hline $\begin{array}{l}\text { Suma de } \\
\text { puntajes }\end{array}$ & 17 & 17 & 20 & 18 \\
\hline Promedio & 3.40 & 3.40 & 4.00 & 3.60 \\
\hline Prioridad & Medio & Medio & Alto & Alto \\
\hline
\end{tabular}

En Julcán se prioriza en un nivel alto los programas de mejoramiento del subsector pecuario en la provincia de Julcán; y en un nivel medio el programa de desarrollo agrícola y el mejoramiento del subsector pecuario en la provincia de Julcán; y en un nivel medio el programa de desarrollo agrícola y el mejoramiento de la infraestructura y tecnificación de riesgo.

En Otuzco se prioriza un programa de infraestructura de riego de la cuenca media alta del río Moche y el programa integral de fortalecimiento del clúster de productos agrícolas tradicionales y alternativos andinos; mientras que en un programa de generación de valor agregado en los productos metálicos (véase Tabla 6).

En la provincia de Pacasmayo se priorizan todos los programas, en especial, el programa de mejoramiento de la infraestructura de riego. En el nivel alto se priorizan el impacto ambiental, novedad del proyecto y la capacidad de realización con nuestros recursos (véase Tabla 7).

En la provincia de Pataz se priorizan el programa de fortalecimiento de las capacidades competitivas de los productores agropecuarios y forestales, en especial en mayor nivel de sostenibilidad ambiental, mientras que en un menor nivel se consideran a la promoción de ferias textiles y artesanales en la provincia de Pataz (véase Tabla 8). 
Tabla 6. Sector económico de la provincia de Otuzco

\begin{tabular}{|c|c|c|c|c|c|}
\hline $\begin{array}{l}\text { Criterios de } \\
\text { Evaluación }\end{array}$ & $\begin{array}{l}\text { Programa de } \\
\text { Mejoramiento } \\
\text { de servicios } \\
\text { turísticos y } \\
\text { actividades no } \\
\text { agropecuarias }\end{array}$ & $\begin{array}{l}\text { Programa de } \\
\text { Infraestructura del } \\
\text { riego de la cuenca } \\
\text { media-alta del río } \\
\text { Moche }\end{array}$ & $\begin{array}{l}\text { Programa de } \\
\text { generación } \\
\text { de valor } \\
\text { agregado en } \\
\text { los productos } \\
\text { metálicos del } \\
\text { distrito de } \\
\text { Salpo }\end{array}$ & $\begin{array}{l}\text { Programa Integral de } \\
\text { fortalecimiento del } \\
\text { clúster de productos } \\
\text { agrícolas tradicionales y } \\
\text { alternativos alto andinos } \\
\text { en la cuenca alta del río } \\
\text { Moche }\end{array}$ & $\begin{array}{l}\text { Programa Integral } \\
\text { de mejoramiento de } \\
\text { la competitividad } \\
\text { del clúster pecuario } \\
\text { en la cuenca media } \\
\text { alta del río Moche }\end{array}$ \\
\hline $\begin{array}{l}\text { Generación } \\
\text { de empleo e } \\
\text { ingresos }\end{array}$ & 4 & 5 & 3 & 3 & 4 \\
\hline $\begin{array}{l}\text { Impacto } \\
\text { ambiental }\end{array}$ & 3 & 4 & 3 & 5 & 4 \\
\hline $\begin{array}{l}\text { Novedad del } \\
\text { proyecto }\end{array}$ & 5 & 3 & 4 & 3 & 3.5 \\
\hline $\begin{array}{l}\text { Capacidad de } \\
\text { realización } \\
\text { con nuestros } \\
\text { recursos }\end{array}$ & 3 & 5 & 4 & 5 & 2 \\
\hline $\begin{array}{l}\text { Impacto en la } \\
\text { reducción de } \\
\text { la pobreza }\end{array}$ & 4 & 5 & 3 & 5 & 4 \\
\hline $\begin{array}{l}\text { Suma de } \\
\text { puntajes }\end{array}$ & 19 & 22 & 17 & 21 & 17.5 \\
\hline Promedio & 3.8 & 4.4 & 3.4 & 4.2 & 3.5 \\
\hline Prioridad & $3^{\circ}$ Alto & $1^{\circ}$ Alto & $5^{\circ}$ Medio & $2^{\circ}$ Alto & $4^{\circ}$ Medio \\
\hline
\end{tabular}

Fuente: Evaluación de criterio priorizada

Tabla 7. Sector económico del provincia de Pacasmayo

\begin{tabular}{|c|c|c|c|c|c|}
\hline $\begin{array}{l}\text { Criterios de } \\
\text { evaluación }\end{array}$ & $\begin{array}{c}\text { Ejecución de } \\
\text { la II etapa de } \\
\text { Proyecto Especial } \\
\text { Jequetepeque- } \\
\text { Zaña }\end{array}$ & $\begin{array}{c}\text { Programa de } \\
\text { capacitación } \\
\text { organizacional } \\
\text { y técnica para } \\
\text { asociaciones } \\
\text { agrarias }\end{array}$ & $\begin{array}{l}\text { Programa de } \\
\text { mejoramiento de } \\
\text { la infraestructura } \\
\text { de riego en la } \\
\text { provincia de } \\
\text { Pacasmayo }\end{array}$ & $\begin{array}{l}\text { Programa para la } \\
\text { reconversión agraria } \\
\text { y mejoramiento de } \\
\text { la productividad } \\
\text { de la producción } \\
\text { agroindustrial en la } \\
\text { provincia de Pacasmayo }\end{array}$ & $\begin{array}{l}\text { Programa de } \\
\text { fomento a } \\
\text { la actividad } \\
\text { turística en la } \\
\text { provincia de } \\
\text { Pacasmayo }\end{array}$ \\
\hline $\begin{array}{l}\text { Generación } \\
\text { de empleo e } \\
\text { ingresos }\end{array}$ & 3 & 3 & 3 & 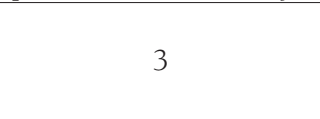 & 4 \\
\hline $\begin{array}{l}\text { Impacto } \\
\text { ambiental }\end{array}$ & 5 & 3 & 5 & & 4 \\
\hline $\begin{array}{l}\text { Novedad del } \\
\text { proyecto }\end{array}$ & 5 & 3 & 5 & 4 & 3 \\
\hline $\begin{array}{l}\text { Capacidad de } \\
\text { realización } \\
\text { con nuestros } \\
\text { recursos }\end{array}$ & 4 & 4 & 5 & 3 & 4 \\
\hline $\begin{array}{l}\text { Impacto en la } \\
\text { reducción de } \\
\text { la pobreza. }\end{array}$ & 5 & 5 & 3 & 3 & 5 \\
\hline $\begin{array}{l}\text { Suma de } \\
\text { puntajes }\end{array}$ & 5 & 18 & 21 & 5 & 20 \\
\hline Promedio & 4.40 & 3.60 & 4.20 & 3.75 & 4.00 \\
\hline Prioridad & Alto & Alto & Alto & Alto & Alto \\
\hline
\end{tabular}

Fuente: Evaluación de criterio priorizada 
Tabla 8. Sector económico del provincia de Pataz

\begin{tabular}{|c|c|c|c|c|c|}
\hline $\begin{array}{l}\text { Criterios de } \\
\text { Evaluación }\end{array}$ & $\begin{array}{c}\text { Programa de } \\
\text { construcción y } \\
\text { mejoramiento de la } \\
\text { infraestructura de } \\
\text { riego en la provincia } \\
\text { de Pataz }\end{array}$ & $\begin{array}{c}\text { Programa de } \\
\text { fortalecimiento de } \\
\text { las capacidades } \\
\text { competitivas de } \\
\text { los productores } \\
\text { agropecuarios y } \\
\text { forestales }\end{array}$ & $\begin{array}{l}\text { Promoción de } \\
\text { ferias textiles y } \\
\text { artesanales en } \\
\text { la provincia de } \\
\quad \text { Pataz }\end{array}$ & $\begin{array}{l}\text { Mejoramiento de } \\
\text { servicio de hostales, } \\
\text { hospedajes y } \\
\text { restaurantes }\end{array}$ & $\begin{array}{c}\text { Programa } \\
\text { de impulso } \\
\text { al sector } \\
\text { pecuario en } \\
\text { la provincia } \\
\text { de Pataz }\end{array}$ \\
\hline $\begin{array}{l}\text { Generación de } \\
\text { empleo e ingresos }\end{array}$ & 5 & 3 & 2 & 3 & 2 \\
\hline $\begin{array}{l}\text { Sostenibilidad } \\
\text { ambiental }\end{array}$ & 4 & 5 & 4 & 5 & 5 \\
\hline $\begin{array}{l}\text { Novedad del } \\
\text { proyecto }\end{array}$ & 3 & 4 & 3 & 5 & 5 \\
\hline $\begin{array}{l}\text { Capacidad de } \\
\text { Realización con } \\
\text { nuestro recursos }\end{array}$ & 2 & 3 & 3 & 2 & 2 \\
\hline $\begin{array}{l}\text { Posibilidad de } \\
\text { financiarlos }\end{array}$ & 4 & 4 & 3 & 1 & 3 \\
\hline Suma de puntajes & 18 & 19 & 15 & 16 & 17 \\
\hline Promedio & 3.6 & 3.8 & 3 & 3.2 & 3.4 \\
\hline Prioridad & 2 & 1 & 5 & 4 & 3 \\
\hline
\end{tabular}

Fuente: Evaluación de criterio priorizada

\section{DISCUSIÓN DE RESULTADOS}

En la provincia de Gran Chimú se priorizan en nivel alto, la forestación con plantaciones maderables y no maderables, en los pisos ecológicos alto y medio y en los corredores económicos priorizados de la provincia. Esto es así porque este sector es uno de los más importantes para el progreso y desarrollo de esta región. Así, el Plan de Desarrollo Regional Concertado de La Libertad (2003) expone el potencial forestal de esta provincia, que cuenta con aproximadamente 57000 has aptas para las plantaciones forestales, destacando el distrito de Cascas (zona de Chepate, Tillampá, Llapo-Samaná y el bosque natural de Cachil y Marmot (Compín) y la parte alta del distrito Chugui-Quilca. De allí que el plan estratégico de desarrollo integral y sustentable (2003) expone como potencial agrícola el clúster de la uva (1700 productores con cerca de 1000 has). Destaca también el cultivo de arroz, maíz amarrillo duro, papa, camote y trigo. Posee 18813 has de área agrícola, de las cuales $25 \%$ están bajo riego y el $75 \%$ en secano.

En conclusión, el Plan de Desarrollo Regional contribuye de manera significativa en el nivel económico de la región La Libertad.

En Otuzco se prioriza un programa de infraestructura de riego de la cuenca media del río Moche y el programa integral de fortalecimiento de clúster de productos agrícolas tradicionales y alternativos andinos. Así, el Programa Regional de Competitividad (2006) expone un potencial agrícola en el que se destacan cultivos altoandinos (papa, menestras, cereales, cebada, trigo, frutales, granadilla, palta, piña). Cuenta con 54535.4 has de áreas 
agrícolas, de las cuales el $32 \%$ se encuentran bajo riego y el $68 \%$ restante en secano. Destacan en producción, los distritos de Otuzco, Salpo y Mache.

En conclusión, un plan de desarrollo integral que potencie estas actividades contribuye de manera significativa en el desarrollo económico de la región La Libertad.

El potencial en el desarrollo de la provincia de Julcán se produce en un nivel alto con los programas de sensibilización y puesta en valor de los recursos turísticos, así como del subsector pecuario en su mejoramiento. Así, el plan de competitividad de la Libertad (2006), se presentan las fuentes de agua como potenciales turísticas, ya que cuenta con 6 lagunas, entre las que destacan las lagunas de Usgón, Brava y Negra, ubicadas en las faldas del cerro Pelón Chico. Para el plan estratégico nacional de turismo (2008), existen zonas en esta región con grandes potenciales turísticos que se van descubriendo para el mejoramiento del sector. El plan de competitividad (2016) nos presenta potenciales forestales y agrícolas, demostrados en su potencial agrícola, ya que cuenta con 42289 has de áreas agrícolas, de las cuales el 16 \% están bajo riego y el 89 \% en secano. Destaca el cultivo de la papa, trigo, cebada en grano y alfalfa. Rivas Majer (2011) explica que Julcán tiene importantes yacimientos minerales. De manera especial, en los distritos de Huaso, Huaynas, Chinchinvara, Unigambal existen zonas mineras de plata, plomo, cobre y zinc. En conclusión, podemos decir que el plan de desarrollo regional contribuye de manera significativa en el nivel económico de la región La Libertad.

\section{Provincia de Santiago de Chuco}

En el aspecto económico, la provincia de Santiago de Chuco se evidencia un plan de desarrollo regional en donde se prioriza el programa de implementación de infraestructura de mayor y menor riego, desarrollando en la generación de empleos e ingresos y el impacto en la erradicación de la pobreza. Según el plan de desarrollo integral de la región La Libertad (2003), en la provincia se destaca el potencial agrícola y el potencial forestal. Se dispone de 265896 has, el 15.58 \% de áreas agrícolas disponiendo de riego solo el 4,31 \% de esta superficie, lo cual limita fuertemente la actividad agropecuaria. Informaciones de la Municipalidad de Santiago de Chuco (2006) señalan que los productos más cultivados son: cereales: trigo, cebada, maíz; tubérculos: papa, oca, olluco; hortalizas y árboles frutales.

En conclusión, el plan de desarrollo regional contribuye significativamente en el aspecto económico de la provincia de Santiago de Chuco.

\section{Provincia de Sánchez Carrión}

Se muestra un plan de desarrollo regional en donde se prioriza en un nivel alto las instalaciones del cultivo de palto, la implementación de obras mecánico-estructurales de la conservación de suelos, los pastos naturales. De allí que para el plan de competitividad de la provincia de Sánchez Carrión (2006) se destaca los potenciales agrícola forestal, en donde se cuenta con 60615 has de esta área agrícola y aproximadamente 72672 has aptas para plantaciones forestales. Asimismo, el plan estratégico de desarrollo de Huamachuco (2001) señala que existen zonas de pasturas, fuentes de agua y zonas minerales. Como 
apreciamos esta provincia mantiene un gran potencial de desarrollo que necesita con planes, proyectos y programas.

En conclusión, el plan de desarrollo regional contribuye de manera significativa en el aspecto económico de la provincia de Sánchez Carrión.

\section{Provincia de Bolívar}

Se evidencia un plan de desarrollo regional, en que se prioriza el programa de mejoramiento y construcción de infraestructura y tecnificación de riego, pero también con una mejor prioridad de servicios turísticos. Es decir, para contribuir con el desarrollo económico se tiene que impulsar este plan de desarrollo como potencial macroestructural. Así, el plan de desarrollo regional concertado (2003) señala como potenciales el agrícola y el forestal, desarrollar las zonas mineras y pasturales, así como sus fuentes de agua. Por su parte, el plan estratégico nacional (2008), mientras que el Cerplan (2009), sostiene que existen grandes yacimientos de minerales. El río Marañón que recorre 100 kilómetros cuenta con atractivos turísticos que levantarían su economía como la fortaleza de Pakarishka y Pirka Pirka. En conclusión, el Plan de Desarrollo Regional contribuye de manera significativa en el nivel económico de la provincia de Bolívar.

\section{Provincia de Pataz}

El plan de desarrollo regional prioriza el programa de fortalecimiento de las capacidades competitivas de los productores agropecuarios, sin embargo no descuida la promoción de ferias textiles y artesanales. Es decir, para contribuir con el desarrollo económico de esta Provincia se tiene que impulsar este plan de desarrollo como potencial macroestructural. En este sentido, el plan estratégico integral (2003) señala como potenciales el sector agrícola y forestal, las zonas de pasturas y minerales, así como las fuentes de agua.

El plan de desarrollo regional (2010) explica que parte de la población se dedica a la extracción de oro. En conclusión, el plan de desarrollo regional contribuye de manera significativa en el nivel económico de la provincia de Pataz.

\section{Provincia de Ascope}

El plan de desarrollo regional prioriza el programa de optimización de riego, su generación de empleo alto; sin descuidar el programa de desarrollo integral del sector turismo, es decir, para contribuir el desarrollo económico de esta provincia se impulsa este plan de desarrollo como potencial macroestructural. De esta manera, el programa regional de competitividad (2006) explica: "Ascope es un pueblo que por ser capital de provincia genera desplazamientos todos los días pero que, lamentablemente, son motivados por trámites documentarios que se realizan, posee las cualidades perfectas para desarrollar diferentes tipos de turismo y de los que sobre la base de sus productos turísticos puede mejorar su actividad económica".

El plan estratégico de desarrollo integral (2003) señala los recursos productivos, agrícola y turísticos contribuyen la base de nuestra grandeza. 
En conclusión, el plan de desarrollo regional contribuye de manera significativa en el nivel económico de la provincia de Ascope.

\section{Provincia de Chepén}

En el plan de desarrollo regional se priorizan todos los programas de reconversión agraria, mejoramiento de la productividad, desarrollo pecuario, turismo. Es decir, para contribuir con el desarrollo económico de esta provincia se impulsa este plan de desarrollo como potencial macroestructural. Así, el programa regional de competitividad (2006) señala que Chepén tiene su base económica en la agricultura, que ocupa el 43,1 \% de la PEA Provincial, cultivando arroz, el maíz y la caña de azúcar que representa el 94 \% de la superficie cosechada. También el plan de desarrollo regional (2010) señala que la industria en proceso de desarrollo, predominando la agroindustria, el turismo se presenta como alternativa para dinamizar la economía provincial. En este sentido, la economía de Chepén está a la vanguardia del progreso y desarrollo de la región que viabiliza el esfuerzo de su gente.

En conclusión, el plan de desarrollo regional contribuye de manera significativa en el nivel económico de la provincia de Chepén.

\section{Provincia de Pacasmayo}

En el plan de desarrollo regional se priorizan todos los programas, como el mejoramiento de la infraestructura de riego, el impacto ambiental y la capacidad de realización con nuestros recursos; en consecuencia, para contribuir con el desarrollo económico de esta provincia se impulsa este plan de desarrollo económico como potencial macroestructural. Así, el programa de competitividad (2006) explica que en el estudio de impacto ambiental, señala que su actividad principal es el comercio, seguido de la manufactura, no cuenta con áreas agrícolas, falta de agua, desarrolla la avicultura, pesca, minería, industria. Es decir, es necesario impulsar el desarrollo económico en forma organizada para levantar sus deficiencias con el nivel económico de la provincia de Pacasmayo.

\section{Provincia de Trujillo}

En el plan de desarrollo regional se prioriza el programa de desarrollo ganadero, el impacto ambiental, desarrollo del proyecto, innovación y mejora de la competitividad de la industria metal-mecánica y la búsqueda constante para reducir la pobreza. En tal sentido, es importante contribuir con el desarrollo económico de esta provincia impulsando el plan de desarrollo regional como motor macroestructural. Así, CCL y WK, UPAO (2010) explica: "Trujillo concentra más del 6,8\% de agentes económicos de los registrados, destaca el sector financiero, minero, eléctrico, de agua, inmobiliario y empresarial".

Asimismo, el plan estratégico de desarrollo integral y sostenible de Trujillo (2003), señala que Trujillo es un centro agroindustrial, que exporta espárragos, el impulso del proyecto CHAVIMOCHIC, en calzado destacan grandes curtiembres. Para el plan estratégico regional exportador (2004) señala que tiene la particularidad de haber conformado un 
conglomerado (clúster) industrial con una dinámica de comercialización y producción propia. En metal-mecánica está compuesto principalmente por pequeñas y medianas empresas, mantenimiento de piezas y carrocerías, pero todavía no ha logrado desarrollar una zona compacta. Asimismo, el plan de desarrollo concertado de La Libertad (2003) expresa que el comercio es una de las actividades más desarrolladas en la ciudad en los rubros de productos agropecuarios, alimentos, bebidas y materiales de construcción, así como desarrolla el comercio exterior en gran medida.

En conclusión, podemos afirmar que un plan de desarrollo regional contribuye significativamente en el nivel económico de la provincia de Trujillo.

\section{Provincia de Virú}

En el plan de desarrollo regional se prioriza el programa de fortalecimiento de capacidades técnicas y organizacionales en pequeños productores agropecuarios, el impacto ambiental y el parque agroecológico y turístico de Guadalupito y Guañape. En consecuencia, es importante contribuir con el desarrollo económico de Virú impulsando el plan de desarrollo regional, como elemento alternativo para potenciar esta zona. Así, el plan de desarrollo concertado de la provincia de Virú (2007) expresa que su agricultura es muy diversa, sembrándose alcachofa, pimiento piquillo, berenjena, espárrago verde y blanco. Presenta importantes atractivos turísticos que al ser explotados adecuadamente contribuirán a beneficiar el desarrollo socioeconómico de la zona. De igual modo, el plan estratégico regional (2009) destaca el complejo arqueológico Zaraque, perteneciente a la cultura Virú, el complejo arqueológico Keneto y los castillos de San Juan y Huancaco y numerosas huacas.

En conclusión, el plan de desarrollo regional contribuye de manera significativa con el desarrollo económico de Virú.

\section{CONCLUSIONES}

a. El nivel económico de los diversos sectores productivos de la región La Libertad requiere priorizar el potencial agroindustrial, forestal, peruano y turístico.

b. Las provincias de la región deben aprovechar al máximo las extensas áreas de cultivo con el desarrollo de proyectos de desarrollo de gran magnitud.

c. Existen algunas provincias que carecen de una auténtica infraestructura que les permita emprender las obras de desarrollo.

d. Se necesita atender en forma prioritaria algunas zonas mineras, ya que constituyen puntales de desarrollo macrorregional.

e. Es imprescindible aumentar la capacidad de riego de muchas provincias de la región La Libertad, así como su tecnificación.

f. Es fundamental ejecutar el Plan de Desarrollo Regional para la región La libertad. 
g. En la región La Libertad para el Plan de Desarrollo Regional se prioriza el programa para la infraestructura y tecnificación del riego en razón de que apenas un promedio del $25 \%$ está en riego y el resto en secano.

h. Las provincias de mayor producción y desarrollo económico son Trujillo, Santiago de Chuco y Pataz; mientras que Bolívar, Pacasmayo, Virú y otros tienen un menor desarrollo económico.

\section{REFERENCIAS BIBLIOGRÁFICAS}

Plan Estratégico Regional del Sector Agrario 2009-2015, Oficina de Planificación AgrariaGerencia Regional de Agricultura. Trujillo, Diciembre del 2008.

Plan Estratégico para la atención de las prioridades regionales en salud 2008- 2012, Gerencia de Salud La Libertad. Trujillo, Julio de 2008.

Plan Regional de Saneamiento Integral para La Libertad, CARE. Trujillo, Junio del 2008.

Plan de Competitividad de La Provincia de Santiago de Chuco, Cámara deComercio y Producción de La Libertad. Trujillo, Diciembre 2006.

Plan Estratégico de Desarrollo Integral y Sostenible de Trujillo, Plandemetru MPT. Actualizado a junio 2003.

Plan Director de Chepén del 2006 al 2011, Municipalidad Provincial de Chepén. Chepén, 2006

Plan Estratégico de Desarrollo Huamachuco al 2018, Municipalidad Provincial de Sánchez Carrión. Huamachuco, 2001

Plan Participativo Regional de Salud de La Libertad 2006-2010 PPR Salud, Consejo Regional de Salud. Trujillo, enero 2006.

Plan Vial Departamental Participativo de La Libertad, Gobierno Regional y Previas. Trujillo, Febrero de 2005.

Programa Regional de Competitividad Región La Libertad, Grupo Impulsor. Trujillo, Julio 2006.

Plan estratégico Regional Exportador, Málaga Web \& Asociados. Trujillo, Marzo del 2004.

Proyecto Educativo Nacional al 2021, Consejo Nacional de Educación. Lima, Enero 2007.

Proyecto Educativo Regional (Primera versión), Consejo Participativo Regional de Educación La Libertad (COPARE-LL). Trujillo, Enero 2007.

Plan de Desarrollo Concertado de la Provincia de Pacasmayo, Municipalidad Provincial de Pacasmayo. San Pedro de Lloc, 2003.

Plan de Desarrollo Concertado de la Provincia de Virú 2007 - 2021, Municipalidad Provincial de Virú. Virú, 2007. 
Plan de Desarrollo Regional Concertado de La Libertad 2003 - 2006, Gobierno Regional de La Libertad. Trujillo, 2003.

Plan Regional de Igualdad de Oportunidades entre Mujeres y Hombres 2006- 2010, Gobierno Regional de La Libertad, 2006.

Plan Estratégico Nacional de Turismo, 2008-2018, Ministerio de Comercio Exterior y Turismo, 2008. 